\title{
Un acercamiento a las investigaciones de la representación de género en la literatura infantil ${ }^{1}$
}

An approach to research on gender representation in children's literature

\author{
Rosalí León-Ciliotta² \\ Universitat Autònoma de Barcelona. Barcelona, España \\ rosali.leon@e-campus.uab.cat
}

Citar como: León Ciliotta, R. (2018). Un acercamiento a las investigaciones de la representación de género en la literatura infantil. Desde el Sur, vol. 10, nro. 2, pp. 347-362.

\section{RESUMEN}

El presente artículo forma parte de una tesis doctoral que analiza libros de literatura infantil que se leen como parte de los planes lectores de primaria en el Perú. La matriz de recolección de datos se construyó a partir de un conjunto de estudios previos que abordan la representación de género desde diversas perspectivas, los cuales se introducen en el artículo a continuación.

\section{PALABRAS CLAVE}

Género, representación de género, literatura infantil, sexismo, roles de género, estereotipos de género

\section{ABSTRACT}

The article is part of a doctoral thesis that analyzes children's literature books included in peruvian Primary School Reading Plans. The data collection matrix was constructed upon previous studies addressing gender representation from different perspectives introduced in the article below.

1 Este artículo es producto de la investigación para la tesis doctoral Representación del género proyectada en libros de literatura infantil de planes lectores de primaria en Perú, bajo el auspicio de la Beca Presidente de la República (Perú).

2 Mg. Rosalí León Ciliotta es editora, escritora y traductora, candidata a doctora en Didáctica de la Literatura Infantil y Juvenil por de la Universidad Autónoma de Barcelona. 


\section{KEYWORDS}

Gender, gender representation, children's literature, sexism, gender roles, gender stereotypes

Desde la introducción de la literatura infantil como un elemento más dentro de la formación escolar de los niños y niñas, esta se presenta como «una agencia educativa, como lo son también, de forma principal, la familia y la escuela» (Colomer, 2010) y se ha asumido como un vehículo para la transmisión de valores, de un estilo de vida (Weitzman et al., 1972) y de la socialización de los estudiantes para formar su personalidad e identidad (Dafflon Novelle, 2003; Garralón, 2011) y desempeñarse en el mundo en que nacieron; como dice Teresa Colomer (2010): «no hay mejor documento que la literatura infantil para saber la forma como la sociedad desea verse a sí misma».

Así, partiendo del reflejo de la sociedad que se presenta en los libros de literatura infantil, vemos los modelos de hombre y mujer a los que los niños y niñas se deben ajustar, lo que usualmente supone un conjunto de roles por cumplir y estereotipos que reproducir, los cuales se basan en la determinación biológica femenina o masculina de los personajes $y$, por extensión, de los jóvenes lectores.

Sin embargo, el prejuicio de género y las disparidades sexuales no solo se manifiestan en los agentes de las historias dirigidas al público infantil y juvenil (es decir, los personajes principales, secundarios y antagonistas de los libros), sino que están también presentes en la forma en que se abordan los diversos temas, el lenguaje que se utiliza y las ilustraciones que complementan los libros para niños (Jett-Simpson y Masland, 1993).

Estudios realizados a lo largo de las últimas cuatro décadas demuestran que hay significativamente más personajes masculinos que femeninos en libros galardonados alrededor del mundo (Colomer, 1994; Davis y McDaniel, 1999; Gooden y Gooden, 2001; Powell, Gillespie, Swearingen y Clements, 1998; Turner-Bowker, 1996; Weitzman et al., 1972), resultado que se repitió cuando se analizaron libros infantiles no galardonados de diversas partes del mundo (Engels, 1981; Nilsen, 1978; Poarch y MonkTurner, 2001).

En la revisión de los títulos de los libros, Shirley Ernst (1995) halló que los nombres masculinos se utilizaban dos veces más a menudo que los femeninos y, más aún, los libros con nombres femeninos en los títulos frecuentemente eran historias de personajes masculinos, situación que se repitió en otras investigaciones. Asimismo, diversos estudios observaron que los escritores utilizaban palabras descriptivas distintas para representar personajes masculinos y femeninos. En un análisis realizado 
por Turner-Bowker (1996), las mujeres generalmente se describían como «bellas, atemorizadas, dignas, dulces, débiles y asustadas», mientras que los hombres se representaban con palabras como «grandes, horribles, feroces, grandiosos, terribles, furiosos, valientes y orgullosos» (TurnerBowker, 199633). Como se hace evidente, las investigaciones sugieren que los hombres también se representan de maneras estereotipadas en la literatura infantil (Diekman y Murnen, 2004; Evans y Davies, 2000; Gooden y Gooden, 2001) y rara vez presentan atributos de personalidad femeninos o toman parte en prácticas o roles considerados como tradicionalmente femeninos.

En cuanto a los álbumes ilustrados, estos muestran un número mayor de hombres que de mujeres (Davis y McDaniel, 1999), y en ilustraciones que retratan a mujeres, ellas se representan con mayor frecuencia realizando tareas domésticas, mientras que los hombres también se presentan de manera estereotipada en cuanto al género: participando en actividades al aire libre, ganándose la vida u operando maquinaria como automóviles (Poarch y Monk-Turner, 2001).

Pese a estos acercamientos desalentadores, algunas investigaciones sugieren que la proporción de personajes masculinos y femeninos se equilibra con el tiempo, a pesar de que todavía hay contrastes significativos (Gooden y Gooden, 2001; Poarch y Monk-Turner, 2001; Powell et al., 1998). Estudios recientes de literatura infantil apuntan a que los escritores y escritoras se esfuerzan por retratar a las niñas y mujeres como personajes femeninos fuertes, que exhiben una gama de emociones menos estereotipadas y son vistas también como astutas, independientes, hábiles y valientes (Heine y Inster, 1999), características y adjetivos tradicionalmente ligados a personajes masculinos. Aunque muchos de estos libros pueden sugerirse como no sexistas, algunos investigadores, como Teresa Colomer e Isabel Olid (2009) o Amanda Diekman y Sarah Murnen (2004), cuestionan si se están evadiendo los problemas de sesgo de género y simplemente representando personajes femeninos que han adoptado personalidades, características y ocupaciones estereotipadas masculinas.

Para profundizar en lo explicado párrafos arriba, las siguientes líneas exponen y resumen, en orden cronológico, las investigaciones que desde hace varias décadas abordan, de manera discursiva o cuantitativa, la representación de género que se proyecta en los libros de literatura infantil, así como de las hipótesis de trabajo de cada investigación.

3 La traducción de esta y las demás citas provenientes de libros en inglés son propias. 


\section{Weitzman et al. (1972)}

Las investigaciones sobre la socialización de género ${ }^{4}$ que se da desde los libros hacia los jóvenes lectores se remontan a inicios de los años 70 . Uno de los primeros estudios focalizados en esta representación de roles y estereotipos de género fue llevada a cabo por las investigadoras Weitzman, Eifler, Hokada y Ross en Estados Unidos (1972). Para este trabajo, centraron su atención en álbumes ilustrados para niños en edad preescolar, pues consideraban que estos tenían un papel importante en la socialización temprana de roles de género al ser vehículos para la presentación y conservación de los valores sociales y culturales (la representación de la sociedad de la que hablan Colomer [2010] y Garralón [2011] en sus respectivos trabajos) desde temprana edad, y persuadir a los niños y niñas de aceptarlos y mantener ciertos estándares aceptables de comportamiento, como bien explica Perriconi (2015) cuando rescata el concepto del desiderátum social del ámbito del psicoanálisis.

Weitzman et al. sostienen que, a través de los libros, los niños aprenden sobre el mundo que les rodea más allá de sus casas o escuelas: la manera en que otros actúan, hablan y sienten. Así, los jóvenes lectores podían intuir, a través de estas historias, lo correcto e incorrecto, y aprender lo que se espera de niños y niñas de su edad. Todo esto se suma a la presentación de modelos a seguir encarnados en los personajes de las historias narradas, de lo que podrían y deberían ser cuando fueran adultos.

Para iniciar su investigación, las académicas consideraron, además, que los libros ilustrados eran de especial importancia en la socialización de género, pues estos suelen leerse una y otra vez en un momento en que los niños y niñas se encuentran en el proceso de desarrollo de sus propias identidades sexuales, cuando son más impresionables, según sostienen.

Para llevar a cabo su análisis estadístico (de títulos, personajes principales, imágenes e historias en general), se centraron en libros ganadores y finalistas del premio Caldecott ${ }^{5}$, y reforzaron la validez de su investigación con la evaluación de libros ganadores del premio Newbery, de la colección Little Golden Books ${ }^{6}$ y de libros de etiqueta social, es decir, aquellos

4 Es un proceso de aprendizaje cultural de los papeles asignados a cada uno según su sexo, en el que las personas aprenden a comportarse de determinadas maneras, según las creencias, valores, actitudes y ejemplos de las sociedades en que viven (Fuente: Unicef).

5 Se trata de un reconocimiento anual otorgado desde 1973 por la Asociación Americana de Bibliotecas que premia a los mejores libros ilustrados para niños en Estados Unidos. Esta medalla supone ventas en decenas de miles, además de ser comprados por casi todas las bibliotecas del país. Junto con la medalla Newbery —que se otorga desde 1922-, el Caldecott es el premio más prestigioso para libros infantiles en Estados Unidos.

6 Esta colección apareció en 1942 en Estados Unidos, y es una de las más y extendidas en el país, con más de mil millones de libros vendidos hasta 2017 (Fuente: Penguin Random House). 
que comunican los comportamientos sociales adecuados para las personas. En sus resultados, lo primero que notaron fue la virtual invisibilidad de las mujeres en los libros: están dramáticamente subrepresentadas en todos los elementos de su análisis. Tan solo en las imágenes, hallaron una proporción de 11 ilustraciones de hombres por cada 1 de mujeres en los libros, tendencia que crece a 95:1 si se habla de libros con animales como personajes. En los títulos, por cada 3 mujeres, había 8 hombres presentes, y en la tercera parte de los libros no había ni una sola mujer en las categorías del estudio (títulos, personajes e ilustraciones). Cuando sí había presencia de mujeres, estas eran usualmente insignificantes o inconspicuas. "Amar, mirar y ayudar estaban entre las pocas actividades permitidas para las mujeres en los libros ilustrados» (Weitzman et al., 1972), y solo 2 de los 18 libros analizados a profundidad en este estudio eran historias sobre mujeres.

En cuanto a las actividades en las que se representaban a niños y niñas, estas se pueden resumir en que los niños eran activos, y las niñas, pasivas. Los roles más aventureros y emocionantes no solo están reservados para los niños, sino que sus objetivos y ansias son más variadas y demandan mayor independencia. Las niñas, por el contrario, suelen estar limitadas por la vestimenta que utilizan (faldas y vestidos que se ensucian fácilmente y que no les permiten mucho movimiento) y se hallan mayormente en el interior, dentro del castillo, detrás de una ventana o de una cerca, o en un pórtico. Mientras las niñas sirven, los niños lideran y actúan; cultivan un sentido de camaradería que no se les permite a las niñas, pese a que este elemento se contradice con la realidad.

Pero las diferencias en la representación del género que encontraron en su análisis no acababan con los niños y niñas. Las investigadoras hallaron que esta tendencia también se repetía en los personajes adultos, quienes aparecían igualmente estereotipados: los hombres se desempeñaban en diversas actividades y ocupaciones, mientras que las mujeres solo aparecían como madres, esposas y amas de casa. Uno de cada 7 hombres realizaba actividades de servicio y ninguna mujer tenía una profesión ni fue presentada en un rol activo o de liderazgo a menos que se tratara de un hada madrina (un ser que no existe en la realidad).

Hacia el final de su investigación, concluyeron que era necesario fomentar la superación de estos roles y estereotipos de género para que niños y niñas pudieran alcanzar su potencial creativo, emocional e intelectual. Asimismo, llamaron la atención sobre el daño que estas inflexibles representaciones de género hacen tanto a niños como a niñas; desde el desarrollo emocional e identitario hasta el limitante rango de aspiraciones que estos modelos idealizados e irreales presentan. 


\section{Teresa Colomer (1994) y Teresa Colomer e Isabel Olid (2009)}

En 1994, Teresa Colomer, investigadora de la Universidad Autónoma de Barcelona, tomó como corpus de investigación 150 libros sancionados por la crítica como los mejores publicados en España desde la década de 1970, y al analizarlos bajo una perspectiva de género halló que casi las dos terceras partes de los protagonistas eran hombres $(62,8 \%)$, menos de la décima parte $(7,7 \%)$ compartían protagonismo y solo la tercera parte tenían protagonistas mujeres (29,5\%).

Cuando los protagonistas eran adultos, se presentaba un mundo mucho más masculino (y algunas veces hasta desaparecían los personajes femeninos), y, a menudo, cuando la mujer realizaba un trabajo fuera de casa, ello era consecuencia de una separación matrimonial.

Con respecto a los antagonistas, encontró que la mayoría eran también hombres, desterrando casi por completo los arquetipos de la madrastra o la bruja malvada, acaso en favor de una presentación menos maniquea del mundo, pero logrando una mayor invisibilización de los personajes femeninos.

A pesar de estos resultados, Colomer concluyó, luego de esta investigación que "Se constata una voluntad equilibradora respecto a los aspectos discriminatorios más externos [pero] aún hay mucho que objetar sobre la igualdad de los modelos ofrecidos a los niños y niñas lectores» (Colomer, 1994).

Una década y media después, la investigadora retomó el estudio de la representación del género en la literatura infantil y juvenil de la mano de Isabel Olid, también docente e investigadora de la Universidad Autónoma de Barcelona, para trabajar sobre las nuevas caras del sexismo en la literatura juvenil y particularmente la chick-lit, el nuevo modelo de literatura para mujeres, industria que representa alrededor del $5 \%$ del mercado editorial de España y más de 35 millones de dólares anuales, y que «recupera [los estereotipos y] la imagen más conservadora de mujer con un barniz de falsa modernidad» (Colomer y Olid, 2009).

Tras su análisis de varias decenas de novelas, las investigadoras notaron quepesealasreivindicacionesfeministasdelasúltimastresdécadasylaintencióndelaseditoriales deliberarsedelcarizdidácticoquesolíatenerlaliteratura dirigida al público juvenil, estas se deslindaron por que el mercado determinase sus principales apuestas de libros, lo que resultó en una regresión en la presencia y profundidad de los personajes femeninos: en gran parte de los libros analizados, durante la primera aparición de los personajes principales y recurrentes femeninos, estos eran descritos de arriba abajo, con una mayor atención al detalle físico que los personajes masculinos, 
y con claras alusiones a aspectos eróticos como la piel o los pechos (reforzando la idea de la belleza inalcanzable para las jóvenes lectoras). Tras la presentación y descripción inicial, poco se sabía de estos personajes femeninos, y un conjunto de características de personalidad se repetían de libro a libro, como la inocencia y la popularidad, o, por el contrario, el rechazo social y el hastío con la vida (de nuevo la dicotomía de mujer virginal vs. mujer de la calle que impera hasta el siglo XX y que investigaciones pasadas notaron al analizar libros infantiles, como se hace evidente a lo largo de este artículo). Rematan Colomer y Olid:

Así que, en definitiva, lo que interesa es simplemente la función ejercida por estos personajes femeninos en la narración. Y el modelo femenino que encarnan... en el imaginario masculino.

En relativo contraste con la desalentadora lectura inicial, el estudio halló también personajes con un prototipo de «mujer iniciadora», donde las chicas pueden ser decididas y desinhibidas, que combinan belleza, sexo, madurez y acción (un ideal de mujer-madre para las investigadoras), pero sin perder la dulzura que caracteriza a las mujeres. Este nuevo prototipo, además de plantear "un nuevo equilibrio de valores entre los géneros» (Colomer y Olid, 2009), permite a los chicos ser vulnerables, más tiernos, desorientados e inexpertos, lo que amplía las formas de masculinidad fomentadas a lo largo de las últimas dos décadas.

Asimismo, observaron dos elementos más que se hacen relevantes porque diferencian a la nueva chick-lit juvenil: por un lado, la irrupción de las supermujeres, que suelen ser guapas, que desprecian la frivolidad, inteligentes y que «son las únicas que parecen tener un cabello anodinamente castaño» (Olid, 2008). Estas compañeras de los héroes, según hallaron, suelen incluso provocar cierto acomplejamiento de sus contrapartes masculinas, y por otro la pervivencia de las femme fatale, chicas independientes, sensuales y activas, que asumen roles tradicionalmente masculinos y que pueden llevar a los chicos de estas narraciones a «encajar en el antiguo papel de las chicas, de modo que rechacen el sexo que las muchachas calcadas de las pantallas parecen tan dispuestas a darles» (Colomer y Olid, 2009). Y sin embargo, estas estampas aparentemente más igualitarias nunca desplazan a la figura masculina, y si se trata de una heroína, «su dureza es solo una pantalla que, aun manteniendo su punto de divertida rareza, tarde o temprano dejará al descubierto su inocencia y necesidad de protección» (Colomer, 2010).

Así, si se trazara una línea evolutiva desde los primeros esbozos de equidad en la representación de género de los años 70 hacia la literatura juvenil actual vemos una engañosa línea de avance: si bien las mujeres ya 
no tienen proscritos los roles activos o las características de inteligencia o sensualidad, las mujeres representadas en la literatura juvenil siguen siendo personajes secundarios, sus ocupaciones, limitadas, y en muchos casos, su aparente modernidad solo enmascara su fragilidad innata y la búsqueda de un happy ending que supone la entrega total al objeto de su afecto.

\section{Association Europèenne Du côtè Des Filles (1998)}

Esta asociación francesa, fundada por la editora y autora Adela Turín, nació en 1994 con el objetivo de eliminar el sexismo de los materiales educativos. Con esto en mente, realizaron una investigación sobre los modelos que transmitían álbumes ilustrados para niños de hasta 9 años bajo la hipótesis de que «Las imágenes, observadas durante mucho tiempo por los niños que todavía no saben leer, son portadoras de estereotipos sexistas» ${ }^{7}$.

Se analizaron estadísticamente 736 álbumes publicados en 1994, provenientes de Francia, Bélgica, España e Italia y se halló que estos presentaban una visión masculina del mundo, con un $61 \%$ de los personajes de sexo masculino, y en la que un promedio de $85 \%$ de los roles y ocupaciones de los padres y hombres en las familias representadas eran de mayor jerarquía que los de las mujeres. De las 255 madres representadas en los álbumes estudiados, solo 14 contaban con una vida profesional que, asimismo, presentaba ocupaciones de menor importancia y tradicionalmente asociadas a las mujeres (escuela, ventas y arte).

Asimismo, notaron una preeminencia de la asignación de características físicas y psicológicas según el sexo, las habilidades y el estatus social. Los personajes masculinos, además, tenían amplia variedad de presencia y roles, mientras que las mujeres se representaban mayormente como inocentes, a veces un poco tontas, en roles subalternos o malvadas. Respecto a paratextos como portadas y títulos, (humanos o animales), más del 75\% de los mismos se referían a personajes masculinos.

Luego de culminado el estudio, se llegó a la conclusión de que los álbumes presentes en hogares y escuelas europeas (en el momento de la realización de la investigación) transmiten e integran a los niños y niñas en estándares sociales sexistas y conservadores, que confinan a las mujeres y las niñas a la esfera privada y los roles pasivos y secundarios, mientras que los hombres y los niños son los protagonistas y ocupan la esfera pública de la vida social (resultado que la psicóloga Anne Dafflon Novelle confirmó en 2003 a través de su propia investigación en la Universidad

7 Fuente: http://www.ducotedesfilles.org/es/cote_filles.html, consultada el 17 de marzo de 2018. 
de Ginebra $\left.{ }^{8}\right)$, y esta visión termina por limitar las potencialidades de expresión e identidad tanto de niñas como de niños.

\section{Diekman y Murnen (2004)}

Tomando como punto de partida el planteamiento de Bussey y Bandura (1999) de que la socialización de género ocurre, en parte, a través de la observación del sistema de recompensa de comportamientos considerados femeninos o masculinos y que este mismo sistema se refleja (de manera distorsionada) en los libros donde aparecen «pequeños hombres» y «pequeñas mujeres», Amanda Diekman y Sarah Murnen decidieron explorar la representación del género que se hacía en libros clasificados como no sexistas, frente a otros considerados sexistas por diversas reseñas, libros y artículos especializados ${ }^{9}$.

Su acercamiento fue de tipo cualitativo, en el que los mismos lectores valoraban, en una escala, ciertos elementos específicos de inequidad de género. Elementos como el tono o actitud frente a situaciones o representaciones sexistas tuvo una especial consideración en esta investigación, en la que se halló que, aunque los libros no sexistas eran más propensos que los libros sexistas a representar personajes femeninos adoptando comportamientos, características y roles estereotípicamente masculinos, ambos (libros sexistas y no-sexistas) representaron de manera similar la personalidad estereotípica femenina, las tareas domésticas y las actividades de ocio.

Su principal hipótesis sostenía que los libros sexistas y no sexistas tendrían la principal diferencia en la representación de la personalidad y roles sociales estereotípicamente masculinos, pues el mayor cambio social ha operado en estos dos ámbitos. Asimismo, esperaban que hubiera una mayor presencia y representación masculina en los libros sexistas, que estos mostraran una mayor segregación de género y que los personajes masculinos ostentaran posiciones y ocupaciones de mayor estatus. Finalmente, debido a la estabilidad del cambio de roles masculinos y femeninos en la sociedad actual, asumían que tanto en los libros sexistas como los nosexistas se presentarían niveles similares de sexismo en dominios estereotípicamente femeninos y en el ideal tradicional femenino.

\footnotetext{
8 Dafflon Novelle, A. (2002). Sexisme dans la littérature enfantine: quels effets pour le développement des enfants? Ginebra: Université de Genève.

9 Se tomaron como base las listas provistas en libros y artículos como Ms. Muffet fights back: A Penguin booklist taking a closer look at gender in children's books (1992); Sexism in reading materials. Reading Teacher, 38 (1985); A children's garden of... diversity (1993), A feminist look at children's books (1972), An analysis of sexism in Newbery Medal Award books from 1977 to 1984. Reading Teacher, 38 (1985), Making the literate environment equitable. Reading Teacher, 40 (1987).
} 
Luego de realizado el análisis, hallaron que en efecto los libros clasificados como sexistas presentaban atributos de personalidad más tradicionales; sin embargo, notaron que esto sucedía con mayor incidencia en los personajes femeninos que en los masculinos. De la misma manera, comprobaron que los libros considerados no sexistas proyectaban una representación más igualitaria de los rasgos de personalidad, aunque esto se notaba más en los personajes masculinos que en los femeninos, los cuales no presentaron gran diferencia en los grupos de libros.

Finalmente, las investigadoras apuntaron que la división más tradicional entre personajes femeninos y masculinos se encontró en las ocupaciones (los personajes femeninos siempre ostentaban un menor rango en el ámbito laboral), luego en las tareas domésticas (mayormente realizadas por personajes femeninos) y por último en las actividades de ocio (que, en general, cumplían con estereotipos tradicionales de género). Confirmaron, además, una de sus hipótesis iniciales: que los roles más estereotipados, tanto en libros sexistas como no sexistas, eran los de los personajes femeninos, hallazgo coherente con otras investigaciones en torno al tema.

\section{Janice McCabe et al. (2011)}

Este estudio partió del planteamiento de que las representaciones de género a través de la historia reproducen y legitiman los sistemas de género $^{10}$. Para probar su hipótesis, McCabe y su equipo analizaron la representación de hombres y mujeres en los títulos y personajes centrales de 5618 libros dirigidos al público infantil publicados a lo largo del siglo XX en Estados Unidos.

Para el análisis presentaron estadísticas descriptivas de medio, moda, rango y ratios de presencia de cada una de las variables en los libros estudiados: hombres y mujeres en los títulos de los libros, por un lado, y personajes dentro de los libros por otro (niños, adultos o animales de cada sexo, y objetos). Se cuantificaron primero por el corpus completo del libro y después desagregándolo por colección y tipo de libro, junto con indicadores para lograr una significancia estadística. Para completar su estudio, hicieron un análisis histórico de tendencias en una línea de tiempo de publicaciones y de eventos sociales relevantes en el tema de representación de género.

10 Los sistemas de género, un concepto acuñado desde la sociología y antropología, son establecimientos arbitrarios de roles de género (elementos simbólicos, patrones de conducta y relaciones sociales) en las diversas sociedades. El binarismo de género (la clasificación del sexo y el género en dos formas distintas y desconectadas: masculinidad y feminidad) es un ejemplo de sistema de género. Se trata de «una forma culturalmente específica de registrar y entender las semejanzas y diferencias entre géneros reconocidos; es decir, en la mayoría de culturas humanas, entre varones y mujeres» (Anderson, J. [1997]. Sistemas de género, redes de actores y una propuesta de formación. Montevideo: CEAAL, p. 19). 
En sus resultados se hizo evidente la disparidad de representación de ambos sexos: en los títulos de los libros, como se adelantaba al inicio de este artículo, los hombres aparecían casi el doble de veces que las mujeres, al tiempo que los personajes centrales masculinos aparecían 1,6 veces más que los femeninos. En ninguna de las colecciones estudiadas (ganadores Caldecott, colección Little Golden Books y el catálogo infantil de Estados Unidos) aparecía una mayor representación de mujeres que de hombres, tendencia que variaba según el tipo de personajes (niños o adultos, humanos o animales), la colección de la que se trataba, y el periodo de publicación de los libros.

Cuando examinaron el rango de cada variable, se vio que en el $100 \%$ de los libros había hombres presentes, mientras que en ninguno de los años (la unidad de medida) la presencia de mujeres superaba el 75\%. Asimismo, hallaron algo incluso más llamativo: a lo largo de cada uno de los años, la presencia de personajes centrales que eran mujeres adultas (humanas o animales) nunca excedió el $33 \%$, mientras que adultos hombres (humanos o animales) aparecieron, de nuevo, en el $100 \%$ de los libros de cada año. Asimismo, la presencia más equitativa se encontraba en los personajes centrales que eran niños, con una proporción de $26,4 \%$ para niños y $19 \%$ para niñas.

Si bien encontraron ciertas diferencias en los rangos de presencia de hombres y mujeres en las colecciones estudiadas, los resultados siempre apuntaban a una mayor representación de personajes masculinos que femeninos. La colección Little Golden Books ${ }^{11}$ presentó mayores desigualdades en la representación de personajes femeninos y masculinos.

Como análisis final, McCabe y su equipo trabajaron una comparación histórica, en relación con eventos sociales relevantes, y encontraron que en las últimas décadas del siglo XX se inició una tendencia significativa hacia la equidad de representación de personajes femeninos y masculinos, tanto en los títulos como en los personajes centrales humanos de los libros, mas no en los personajes animales, que siguen mostrando una preeminencia de representación masculina.

\footnotetext{
11 Para la propia investigadora, esta colección es la que presenta los valores más tradicionales en términos de roles y estereotipos de género, hipótesis que se confirmó cuando llevó a cabo el análisis de la representación del género. Esta diferenciación puede ser de utilidad al momento de comparar los tres corpus que componen la presente investigación de libros de planes lectores del Perú, partiendo de la hipótesis de que las escuelas públicas son aquellas que eligen libros más «clásicos», que transmiten los valores más tradicionales en cuanto al género.
} 


\section{Chick, Slekar y Charles, y Chick y Corle (2010 y 2012)}

Estas investigaciones analizaron, desde la perspectiva de género, los libros reconocidos por el NCSS (las siglas en inglés del Consejo Nacional para los Estudios Sociales) como notables en la categoría de álbumes ilustrados, por un lado, y de libros para grados intermedios ${ }^{12}$, por otro, en los años 2006-2008.

Ambos estudios utilizaron la misma metodología cuantitativa de recolección de datos, pero, a diferencia del estudio de álbumes ilustrados, en el estudio que abordó los libros para grados intermedios (Chick y Corle, 2012) se agregaron las características de personalidad y roles y ocupaciones que las investigadoras consideraron pertinentes del estudio llevado a cabo por Diekman y Murnen en 2004 (desarrollado páginas arriba), y que también se ha tomado en consideración para la recolección de datos en la tesis doctoral que da origen a este artículo.

En ambos estudios (Chick, Slekar y Charles, y Chick y Corle) se examina el número de personajes masculinos y femeninos y la presencia o ausencia de estereotipos de género en relación con sus personalidades, ocupaciones y comportamientos. Los resultados evidenciaron una diferencia significativa en el número de personajes masculinos y femeninos en favor de los personajes masculinos, además de un desbalance en el número de libros que solo presentaban personajes hombres (sobre el $25 \%$ ) frente a menos del $10 \%$ de libros con solo personajes mujeres, aunque más de la mitad tenían personajes de ambos sexos. Asimismo, en ninguno de los libros examinados por los dos estudios se representó a hombres en puestos de menor estatus que los de las mujeres, como ya habían notado McCabe y su equipo en su investigación de 2011, abordada en el apartado anterior.

Tanto los hombres como las mujeres en los dos grupos de textos analizados (álbumes ilustrados y textos para grados intermedios) realizaban con frecuencia trabajos relacionados tradicionalmente con el sexo de los personajes. Entre otros resultados relevantes, notaron que, por un lado, tanto hombres como mujeres se presentaban mayormente en roles estereotipados, y, por otro, muchas de las mujeres no tenían una variedad de actividades laborales ni trabajos u ocupaciones consideradas aventureras (como exploradoras o cazadoras), algo que Teresa Colomer (1994) ya había notado una década y media antes en libros españoles.

12 En el sistema de educación básica de Estados Unidos, los grados intermedios abarcan de quinto a octavo de la educación básica regular, grados compuestos por niños y niñas de entre 10 y 14 años. 
Una diferencia significativa entre los hallazgos de los dos estudios motivo de este apartado recae en el cruce de las líneas tradicionales de género: los libros para grados intermedios mostraron a un $30 \%$ de mujeres en roles no tradicionales, mientras que, en los álbumes ilustrados, este cruce de fronteras (de roles tradicionales de género) se daba mayormente en aquellos que solo tenía personajes centrales femeninos.

Para el desarrollo de ambos estudios, se crearon hojas de codificación en las que se establecieron 17 comportamientos predeterminados para los personajes a lo largo de los libros, y en siete de ellos se mostraron diferencias significativas entre hombres y mujeres. Los hombres tenían más probabilidades de participar en deportes, pelear en batallas o demostrar comportamientos agresivos, así como perseguir causas valiosas, usar medios de comunicación y aparatos tecnológicos y ganarse la vida. Por el contrario, las mujeres eran más propensas a realizar tareas domésticas y demostrar afecto o emoción. Esta tendencia, sin embargo, se redujo en los libros para grados intermedios, lo que apunta a un pensamiento más independiente y encaminado a dejar atrás los roles y estereotipos tradicionales de género. Lo mismo sucedió con las expresiones de emoción o de afecto en los personajes y en su uso de la tecnología: no hubo gran diferencia entre hombres y mujeres en estos dos elementos, predisposición que se hizo notar en el estudio con álbumes ilustrados.

En las conclusiones de ambos estudios hipotetizaron que varios de los desbalances mostrados en los libros provinieron de las casas editoriales y no de los autores y autoras, como se hace evidente en la cita con la que cierran sus investigaciones, de la autora Mem Fox (1993):

Nosotros, los que escribimos libros para niños, y los que enseñamos a través de la literatura, necesitamos estar seguros de que estamos abriendo las puertas para realizar el pleno potencial humano, no cerrándolas. Tenemos el poder de cambiar los comportamientos y las actitudes apropiadas para cada género, y aun así, muchos de nosotros parecemos estar ciegos ante la oportunidad.

A manera de reflexión final, si adoptamos una perspectiva de evolución histórica de los estudios de la representación del género en los libros infantiles, podremos ver que, si bien las fronteras entre los roles y estereotipos de género se traspasan lentamente, aún queda mucho por avanzar en el ámbito de la paridad en la presencia y representación de personajes femeninos y masculinos. Por un lado, se están construyendo nuevos modelos de masculinidad que incluyen rasgos o características tradicionalmente asociadas a lo femenino, pero por otro no se amplían de manera equitativa los modelos de femineidad, lo que resulta en una falta 
de modelos positivos y constructivos para las mujeres en lugar de una perfilación difusa del género, en el que las mujeres simplemente adoptan roles y estereotipos masculinos mientras que aquello que tradicionalmente representó a la femineidad se desaparece o se relega a una percepción de lo negativo y aquello que se debe evitar para ambos géneros.

\section{Contribución del autor}

Rosalí León ha participado en la concepción del artículo, la recolección de datos, su redacción y aprobación de la versión final.

\section{Fuente de financiamiento}

Autofinanciado.

\section{Conflictos de interés}

La autora declara no tener conflictos de interés. 


\section{REFERENCIAS BIBLIOGRÁFICAS}

Bussey, K. y BandurA, A. (1999). Social cognitive theory of gender development and differentiation. Psychological Review, vol. 106, nro. 4, pp- 676713. Recuperado de https://doi.org/10.1037/0033-295X.106.4.676

Colomer, T. (1994). A favor de las niñas: El sexismo en la literatura infantil. Cuadernos de Literatura Infantil y Juvenil, vol. 7, nro. 57, pp. 7-24.

Colomer, T. (2010). Introducción a la literatura infantil y juvenil actual. Madrid: Sintesis.

Colomer, T. y Olid, I. (2009). Princesitas con tatuaje: las nuevas caras del sexismo en la ficción juvenil. Textos de Didáctica de La Lengua y La Literatura, vol. 51, pp. 55-67.

Dafflon Novelle, A. (2003). Sexisme dans la littérature enfantine: quels effets pour le développement des enfants? Recuperado de http://mediatheque.seine-et-marne.fr/library/Sexisme-Litterat-Enfants

Davis, A. y McDaniel, T. (1999). You've come a long way baby- or have you? Research evaluating gender portrayal in recent Caldecott-winning books. The Reading Teacher, vol. 52, nro. 5, pp. 532-536.

Diekman, A. B. y Murnen, S. K. (2004). Learning to be little women and little men: The inequitable gender equality of nonsexist children's literature. Sex Roles, vol. 50, nros. 5-6, pp. 373-385. Recuperado de https://doi. org/10.1023/B:SERS.0000018892.26527.ea

Engels, R. (1981). Is unequal treatment of females diminishing in children's picture books? The Reading Teacher, vol. 34, nro. 6, pp. 647-652.

Ernst, S. (1995). Gender issues in books for children and young adults. In S. Lehr (Ed.), Battling dragons: Issues and controversy in children's literature (pp. 66-78). Portsmouth: Heinemann.

Evans, L. y Davies, K. (2000). No Sissy Boys Here: A Content Analysis of the Representation of Masculinity in Elementary School Reading Textbooks. Sex Roles, vol. 42. nros. 3-4, pp. 255-270. Recuperado de https://doi. org/10.1023/A:1007043323906

Garralón, A. (2011). Literatura con valores. Recuperado de http://www. cervantesvirtual.com/obra-visor/literatura-con-valores-0/html/fff72c6282b1-11df-acc7-002185ce6064_2.html\#l_1_

Gooden, A. M. y Gooden, M. A. (2001). Gender representation in notable children's picture books: 1995-1999. Sex Roles, vol. 45, nros. 1-2, pp. 89101. Recuperado de https://doi.org/10.1023/A:1013064418674

Heine, P. e Inster, C. (1999). Strong female characters in recent children's literature. Language Arts, vol. 76, nro. 5, pp. 427-434. 
Jett-Simpson, M. y Masland, S. (1993). Girls are not dodo birds! Exploring gender equity issues in the language arts classroom. Language Arts, vol. 70, nro. 2, pp. 104-108.

Nilsen, A. (1978). Five factors contributing to the un-equal treatment of females in children's picture books. Top of the News Spring, vol. 2, pp. 255258.

Olid, I. (2008). Entre nois i noies: la força dels estereotips. La nova chick lit per a adolecents. In T. Colomer (Ed.), Lectures adolescents (pp. 167-182). Barcelona: Graó.

Perriconi, G. (2015). La construcción del género en la literatura infantil y juvenil. Buenos Aires: Lugar Editorial.

Poarch, R. y Monk-Turner, E. (2001). Gender Roles in Children's Literature: A Review of Non-Award-Winning «Easy-to-Read» Books. Journal of Research in Childhood Education, vol. 16, nro. 1, pp. 70-76.

Powell, J., Gillespie, C., Swearingen, R. y Clements, N. (1998). The history of gender roles in Newbery medal winners. Journal of Children's Literature, vol. 24 , nro. 1, pp. $42-57$.

Turner-Bowker, D. M. (1996). Gender stereotyped descriptors in children's picture books: Does «Curious Jane» exist in the literature? Sex Roles, vol. 35, nros. 7-8, pp. 461-488. Recuperado de https://doi.org/10.1007/ BF01544132

Weitzman, L., Eifler, D., Hokada, E. y Ross, C. (1972). Sex-role socialization in picture books for preschool children. American Journal of Sociology, vol. 77, nro. 6, pp. 1125-1150. 